\title{
TECENDO CONTRIBUIÇÕES ACERCA DOS SHOPPING CENTERS NO TERRITÓRIO METROPOLITANO DE FORTALEZA-CEARÁ
}

\author{
Tiago Estevam Gonçalves ${ }^{1}$
}

\begin{abstract}
Resumo: A temática dos shopping centers se insere no bojo das transformações ocorridas no âmbito do comércio, associada à dinâmica imobiliária e financeira. $\mathrm{O}$ artigo ora proposto tem como objetivo analisar os shopping centers no atual estágio de metropolização de Fortaleza. Parte-se da concepção de que as relações entre metrópole, shopping center, produção espacial e consumo são bastante estreitas, estando atreladas às novas dinâmicas de internacionalização da economia mundial. $\mathrm{O}$ artigo tem como instrumental reflexivo as categorias, as dinâmicas e os processos espaciais ligados ao imobiliário-terciário.
\end{abstract}

Palavras-chave: Shopping Center; Dinâmicas Metropolitanas; Produção espacial.

\section{WEAVING CONTRIBUTIONS ABOUT THE SHOPPING CENTRES IN THE METROPOLITAN AREA OF FORTALEZA-CEARÁ}

\begin{abstract}
The theme of the shopping centres inserts in the midst of the transformations occurred in the in trade associated with the real estate and financial dynamics. The article proposed here aims to analyze the shopping centres of the current stage of the metropolis Fortaleza. It starts with the relationship between the metropolis, shopping centre, space production and consumption that are quite narrow, is linked to the new dynamics of internationalization of the world economy. The article has as reflective instrumental the categories, the dynamic and the spatial processes related to real estate-tertiary.
\end{abstract}

Keywords: Shopping Centre; Dynamic metropolitan; Production Space.

\section{TEJIENDO APORTES ACERCA DE LOS CENTROS COMERCIALES EN EL TERRITORIO METROPOLITANO DE FORTALEZA-CEARÁ}

Resumen: La temática de los centros comerciales se inserta en el seno de las transformaciones ocurridas en el ámbito del comercio, asociada a la dinámica inmobiliaria y financiera. El artículo propuesto tiene como objetivo analizar los centros comerciales en la actual etapa de metropolización de Fortaleza. Se parte de la concepción de que las relaciones entre metrópoli, centro comercial, producción espacial y consumo son bastante estrechas, estando vinculadas a las nuevas dinámicas de internacionalización de la economía mundial. El artículo tiene como instrumental reflexivo las categorías, las dinámicas y los procesos espaciales ligados al inmobiliario-terciario.

Palabras clave: Centro comercial; Dinámicas Metropolitanas; Producción espacial.

\footnotetext{
${ }^{1}$ Professor do Instituto Federal de Educação, Ciência e Tecnologia do Ceará-IFCE. Doutor em Geografia pela Universidade Federal do Ceará-UFC com período de estágio de doutoramento no Instituto de Geografia e Ordenamento do Território da Universidade de Lisboa.
} 


\section{INTRODUÇÃO}

No bojo das atividades terciárias na contemporaneidade, o urbanismo comercial com a presença e avanço dos shopping centers, tanto no mundo desenvolvido quanto no mundo em via de desenvolvimento, de maneira diacrônica e sincrônica, é permeado de novas lógicas que influenciam significativamente na alteração dos hábitos de consumo, bem como, no ordenamento territorial urbano-metropolitano. Considera-se que seja salutar discutir a respeito dos shopping centers inserido nas transformações ocorridas no âmbito do comércio, associados à dinâmica imobiliária e financeira dos espaços urbanos.

Os shopping centers no desenvolvimento urbano e metropolitano são considerados equipamentos de grande de porte que atuam consideravelmente na alteração do espaço urbano, desse modo faz parte do rol de temáticas com elevado grau de importância para o entendimento da cidade e da metrópole na atualidade. Os shopping centers com temática selecionada para estudo se insere no bojo das transformações ocorridas no âmbito do comércio, não entendido isoladamente, mas sim, associado ao âmbito imobiliário e financeiro, e por sua vez, inserida no conjunto da produção geral da sociedade, que no processo contemporâneo se coloca, cada vez mais, no âmbito da sociedade urbana.

Parte-se da concepção de que os shoppings se constituem importantes territórios do simulacro de consumo nas metrópoles contemporâneas. Sabe-se, pois, que as atividades comerciais têm sua diversidade materializada e imbricada de símbolos e signos. Nesse sentido, poder-se-ia utilizar outros exemplos de território de consumo, como, os hipermercados, supermercados e espaços voltados para o turismo, no entanto, optou-se pelos shoppings, por eles representarem um modelo de consumo e comércio que extravasa os paradigmas da modernidade, apresentando características de convergência de manifestação do espetáculo da mercadoria. Estes simulacros ganham notoriedade no contexto de consumo na pós-modernidade e tornam-se centros em que reinam a verdadeira utopia urbana da perfeição e da realização dos desejos e efetivação do consumir.

Imbuídos da busca de aprofundamento sobre o tema, tenta-se abordar visões diversas, entretanto complementares que possibilitem o entendimento de modo dialético e complexo da realidade vivida, percebida e concebida nestas grandes superfícies comerciais. O artigo tem por objetivo analisar os shopping centers como territórios de consumo no atual estágio de 
metropolização de Fortaleza, tendo como instrumental reflexivo, as categorias, as dinâmicas e os processos espaciais ligados ao imobiliário-terciário.

Assim sendo, consideram-se os shoppings como produto comercial-imobiliário que possuem relações diretas no crescimento e transformação do espaço urbano-metropolitano, ou seja, atuando deste modo como elemento dinâmico produtor de modificações do território metropolitano; bem como, o consumo na organização da sociedade atual perpassando novas relações sociais de consumo que tem como palco das realizações - os shoppings - sendo que a produção se justifica como função da componente de realização do consumidor nestes territórios de consumo.

As formas do comércio se mostram como complexidades socioespaciais, pois são produtos históricos, desenvolvidos ao longo da existência humana em uma busca constante de meios e respostas rápidas e eficazes para satisfação das necessidades de vida, que no caso da sociedade capitalista são, antes de qualquer coisa, as necessidades do capital e é evidente que isso não se faz sem as pessoas, mas o objetivo final é a reprodução ampliada do capital.

O comércio tem sido cada vez mais encarado como uma verdadeira função urbana estreitamente relacionado com processos de metropolização, assim, tem deixado bem evidenciado valências e dinâmicas que extravasam a mera função econômica. As atividades comerciais sempre estiveram associadas ao desenvolvimento urbano, o estudo sobre o setor terciário avançado está imbricado de novos atores e agentes imobiliários e financeiros, que possibilitam compreender as transformações ocorridas nas relações entre as atividades econômicas e na vida urbana, cujo consumo tem tido novas perspectivas de significado na sociedade contemporânea.

Vivencia-se uma cultura da apreciação pelo materialismo, em cujo contexto há uma inserção das mercadorias no dia-a-dia das pessoas, ultrapassando as barreiras da compra-econsumo instantâneo, estendendo a vida e a durabilidade de seus pertences a uma rotina diária, criando um verdadeiro elo entre consumidor e produto. Nesse contexto, os shoppings podem, assim, ser associadas às tendências da privatização, homogeneização social e fragmentação espacial. Ao considerar as mudanças na sociedade contemporânea, diante da economia urbana, nota-se um novo quadro com o processo de globalização e de reestruturação produtiva do capital em que as atividades terciárias passam a ter um papel 
relevante, com isso, torna-se pertinente o estudo sobre a temática do comércio e do consumo no âmbito geográfico dos shoppings.

\section{PRESSUPOSTO TEÓRICO-METODOLÓGICO}

A Geografia Urbana, como ramo da ciência que se preocupa em desvendar os problemas e as características formais, funcionais e estruturais do espaço metropolitano, tem na metropolização contemporânea de Fortaleza, impulsionada pela criação de modernos equipamentos - como os shopping centers -, um amplo terreno de pesquisa. Como Silva (1992) destaca, a Geografia urbana tem-se voltado para a análise social, em que a estruturação e a reestruturação urbanas exercem verdadeiro fascínio sobre os geógrafos desse setor da ciência geográfica. Desse modo, essa área do conhecimento científico tem buscado compreender os espaços geográficos das cidades como um espaço social, resultado e parte de uma sociedade constituída de grupos socioeconômicos.

O conhecimento científico nasce possivelmente da busca do ser humano em ter um controle e poder de ação sobre os fenômenos e fatos, possuindo dessa maneira um papel ativo, e não uma posição de mero espectador daquilo que ocorre à sua volta. Nesse sentido, usando de suas potencialidades de racionalidade, cabe ao ser humano conceber de modo sistemático uma leitura, ou melhor, uma compreensão do mundo, utilizando os métodos de investigação e de aplicação.

Nesse contexto, é salutar destacar que um dos grandes interesses do ser humano pela ciência se dá pela constante curiosidade de entender as relações que existem entre as ocorrências e o que existe por detrás das aparências. Nesse âmbito, podemos pensar na construção do espaço - categoria de análise da pesquisa ora proposta - e na relação entre sociedade e natureza. É imprescindível que se busque não somente a aparência - o material -, mas também o imaterial, aquilo que somente a essência pode oferecer como perspectiva analítica do espaço.

O pressuposto teórico-metodológico desta pesquisa apoia-se em Henri Lefebvre, tendo como categoria analítica o espaço, mais especificamente a produção do espaço urbanometropolitano. A investigação tem por base a leitura do trabalho de Henri Lefebvre (2004). A 
pesquisa se desenvolve, inicialmente, do tempo presente para o passado, no intuito de destacar fatos que esclareçam o presente, observando o desencontro das temporalidades, os contrapontos entre o tradicional e o (pós)moderno, as continuidades e as descontinuidades do espaço urbano e metropolitano. Na elaboração desta pesquisa foi feita uma periodização do tempo, para possibilitar o entendimento desses desencontros temporais e dessas descontinuidades espaciais.

O espaço, ao se reproduzir, se materializa em vários momentos históricos ao mesmo tempo de maneira desigual, atribuindo diferenças entre esses espaços. Assim, compreender o espaço implica raciocinar as diferenças espaciais e as características que se descobrem expostas ou implícitas no espaço.

Desse modo, cada acontecimento ou especificidade espacial deve ser analisada sob a articulação dos processos socioespaciais, que possibilitam uma leitura acurada do presente urbano e metropolitano fortalezense. Nesta pesquisa tem-se como objetivo analisar a dinâmica de metropolização de Fortaleza, a partir dos shoppings centers, sendo o recorte temporal o período entre 1974 e 2014. Sabendo que parte significativa do momento atual possui relação com o passado, parte-se do presente em direção ao passado (a partir da instalação dos primeiros shoppings em Fortaleza e RMF), mirando não apenas explicar o passado no sentido de história, mas, sobretudo, almejando o entendimento dos processos socioespaciais em movimento do presente que apontam para o futuro. Assim, perseguem-se os esclarecimentos dos processos em curso no presente para vislumbrar o que está por vir.

O processo de metropolização de Fortaleza foi estudado sob diferentes prismas pelos autores acima citados. Costa (2005), ao realizar um estudo sobre o conjunto habitacional Cidade 2000, contribui para o entendimento da formação de Fortaleza, a relação da participação do Estado no direcionamento de investimentos, bem como a posterior formação desse conjunto e a atuação dos investimentos privados na produção imobiliária.

A operacionalização da pesquisa envolveu a recolha de informação num conjunto muito diversificado de fontes documentais. Em relação à urbanização, destacam-se a Biblioteca Pública Menezes Pimentel; o Laboratório de Estudos Urbanos e Geografia Cultural (Leur), da Universidade Estadual do Ceará; o Laboratório de Planejamento Urbano e Regional (Lapur), do Departamento de Geografia da Universidade Federal do Ceará; a Prefeitura Municipal de 
Fortaleza, em órgãos como a Secretaria de Planejamento de Fortaleza (Sepla) e a Secretaria Municipal de Desenvolvimento Urbano e Infraestrutura (Sefin).

Foram realizados levantamentos cartográficos, com observação de imagem de área, no intuito de localizar os shopping centers e os empreendimentos que estão atrelados à sua implantação. A partir disso, confeccionaram-se os primeiros mapas de localização, possibilitando uma leitura sobre as novas lógicas de produção desse terciário moderno.

Após a coleta de todos os dados necessários - documentos, mapas, fotografias, periódicos, livros, monografias, dissertações, teses, entre outros -, armazenaram-se as informações em um banco de dados, a fim de facilitar a análise do material a ser usado, etapa essencial na construção da pesquisa, pois o acervo selecionado deverá ser pertinente ao desenvolvimento da investigação, de modo que possa fundamentar o artigo de forma coerente e concisa.

\section{O TERRITÓRIO METROPOLITANO DE FORTALEZA: FORMAÇÃO, PERMANÊNCIAS E MUDANÇAS}

No processo de oficialização das regiões metropolitanas no Brasil, em 1973, a Região Metropolitana de Fortaleza (RMF) foi estabelecida. A capital firma-se como uma metrópole do estado do Ceará e uma das principais da região Nordeste. No início a área metropolitana de Fortaleza era formada por apenas cinco municípios: Aquiraz, Pacatuba, Maranguape, Caucaia e Fortaleza. Em termos políticos-administrativos, a RMF sofreu transformações devido aos processos de desmembramentos e da agregação de outros municípios a região. A oficialização da Região Metropolitana de Fortaleza foi do tipo compulsório, instituída e definida por força legal.

A metropolização ao mesmo tempo em que abriu a possibilidade de alteração dos limites das regiões metropolitanas existentes, ou seja, incluindo ou mesmo excluindo municípios, desencadeou um contínuo ciclo de institucionalização de novas unidades regionais, com diferentes portes de população, considerando até pequenas aglomerações urbanas, e as classificando como metropolitanas (GONÇALVES; COSTA, 2012).

Neste contexto, a última ampliação institucional da RMF se deu a partir da Lei complementar $n^{\circ}$ 144, de 04 de setembro de 2014, quando a Região Metropolitana de Fortaleza passou por alterações, incorporado os seguintes municípios: Paraipaba, Paracuru, São Luís do Curu e Trairi, que junto com 
os municípios de: Aquiraz, Caucaia, Eusébio, Guaiúba, Fortaleza, Horizonte, Itaitinga, Pacatuba, Pacajus, Chorozinho, Maranguape, Maracanaú, São Gonçalo do Amarante e Fortaleza formam a atual RMF, sendo composta por um total de dezenove munícipios (Figura 01).

Figura 01: Mapa da evolução político-administrativa da Região Metropolitana de Fortaleza

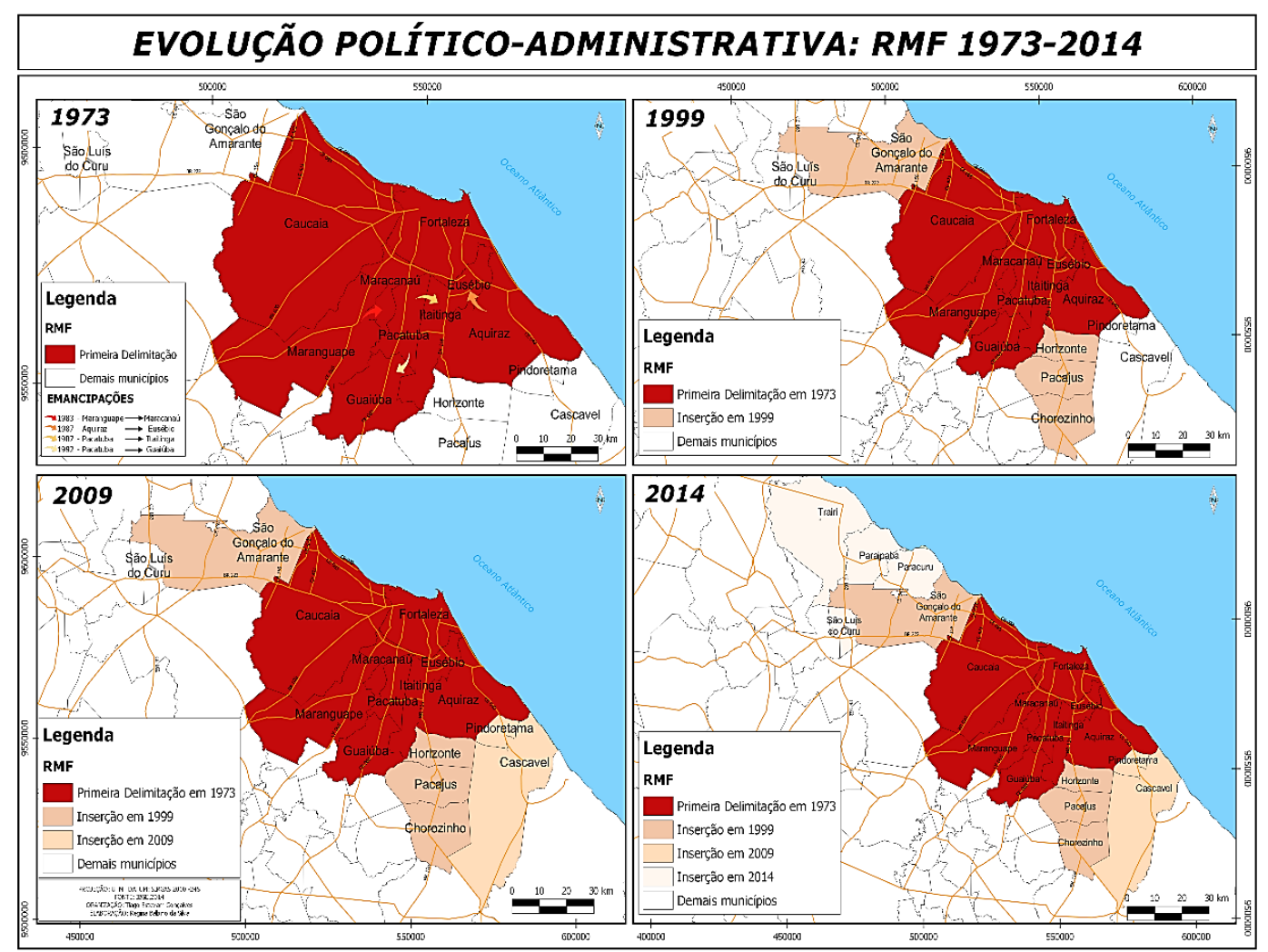

Fonte: Autor, 2015.

No âmbito desta reflexão a pesquisadora Lencioni (2005) afirma que para entender alguns casos específicos de grandes aglomerados urbanos é necessário transcender o entendimento do processo de urbanização, precisando estudar de forma apurada a metropolização do espaço, "Neste processo de metropolização do espaço é que reside a nova rede de relações que permite reconstituir, do ponto de vista teórico, a unidade entre cidade de região". (LENCIONI, 2005, p.35). Parafraseando Ascher (1998, p.40), “A metropolização 
aparece como uma etapa ou uma fase no processo de urbanização supra histórico, e a metápolis como uma forma urbana co-estuturada pelo uso de novas técnicas de comunicação, de conservação e de deslocamento dos bens, das pessoas e das informações".

Poder-se-ia dizer que o processo de metropolização se realiza em primeiro lugar, como processo de acumulação primitiva produzindo enormes déficits urbanísticos e diferenças sociais profundas que, como reservas de solo urbano e força de trabalho, alimenta depois, nos momentos em que começam a diminuir as taxas de crescimento demográfico e de expansão urbana, o processo de acumulação da metrópole inserido na lógica expansionista geral de um sistema capitalista, no qual domina a acumulação incessante de capital e a busca interminável do lucro, que dá lugar à pretensão perpétua de criar um contexto geográfico que facilite as atividades capitalistas num lugar e momento determinados, só para ter que construir um contexto totalmente diferente num momento posterior, sem poder saciar nunca sua perpétua sede de acumulação (HARVEY, 2005).

\section{O TERCIÁRIO NO CONTEXTO METROPOLITANO}

Na sua materialidade a metrópole é a síntese mais complexa da conexão espaço-tempo porque no seu processo de formação o tempo passou a ter como base o aspecto social, conduzido pela lógica da globalização financeirizada, a qual resulta no aprofundamento da divisão do trabalho e da generalização da economia de trocas. A formação da metrópole equivale ao movimento da própria formação social que ocorre dilacerando as formações pretéritas, tanto de cidades como de subúrbios e alcançando, sobretudo, as entranhas da cidade, embora apenas algumas cidades cheguem de fato à condição de metrópole (SEABRA, 2011).

A metrópole, portanto, possui um caráter de centralidade em que detém a concentração das atividades de produção, conhecimento e serviços, bem como, é difusora de inovações estruturais, tecnológicas e culturais. Em termos de escala são nas metrópoles (plano do local) que ocorrem as maiores convergências de fluxos econômicos internacionais (plano do global).

A metrópole é o centro de comando da economia e da política, das atividades culturais e de pesquisa. É a cidade mais importante de uma região ou país, concentrando os principais 
empreendimentos comerciais e financeiros e estendendo suas influências sobre amplos trechos do território. É o principal elo com o exterior, em razão de sua força econômica e de sua infraestrutura diversificada, com ampla rede de hotéis, e geralmente, aeroportos equipados e sistemas de telecomunicações eficientes. (COSTA, 2005; SOUZA, 1995; GONÇALVES; COSTA, 2012).

Neste sentido, na visão perspicaz e densa de Silva (2005), considera-se que Fortaleza afirma-se como metrópole regional e como uma das principais aglomerações da rede urbana brasileira. Desenvolve-se como um núcleo centralizador caracterizado por uma diversidade de funções (multifunções) e que possui relações econômicas com muitos centros urbanos no patamar nacional e internacional. Nesta mesma linha Pereira Júnior (2013) concorda com as concepções de Silva (2005), ao considerar os espaços metropolitanos como resultado da influência de uma metrópole sobre amplas dimensões territoriais, extrapolando os limites político-administrativos e configurando tecidos urbanos contínuos ou descontínuos.

O crescimento de Fortaleza está diretamente relacionado ao desenvolvimento do setor terciário que tem a primazia sobre as demais. Concentrando o excedente do setor primário, a cidade se constitui em centro de coleta da produção agrícola e distribuidor de bens e serviços a uma vasta área, que extravasa os limites do Estado. O predomínio do setor terciário de Fortaleza fez com que a sua configuração espacial urbana tivesse influência nas relações da cidade com sua região metropolitana, bem como, com o exterior (SOUZA, 2009).

[...] O comércio e a prestação de serviços, que lhe conferiram historicamente a condição de polo regional, ao extrapolar os limites administrativos do estado do Ceará, se expandiram, nas últimas décadas, gerando novos fluxos e impactando na diversificação e consolidação do espaço metropolitano. Complexifica suas funções, desenvolve os setores da sua econômica urbana, e, desse modo, se insere hierarquicamente no contexto nacional e internacional, à medida que se apoia em uma base territorial [...] (COSTA; AMORA, 2015, p.35).

Ressalta-se o poder regionalizante das atividades terciárias que se dá em função do comércio e serviços, sendo que seu raio de influência se estende em direção a cidades vizinhas. Neste contexto, Bernal (2009) considera que as transformações estruturais que vêm ocorrendo em Fortaleza, principalmente, a partir dos anos 1980, apontam para uma tendência parecida com a que ocorre em outras metrópoles, não sendo uma cidade que se tenha firmado 
devido ao desenvolvimento industrial, no entanto, observa-se o processo avançado como cidade terceirizada de Fortaleza, na qual se destaca pela atividade comercial e serviços, tendo um peso significativo na empregabilidade da população economicamente ativa.

O terciário influencia fortemente as cidades, de modo que as relações pautadas entre comércio e cidade vão ganhando uma complexidade de análise, pois se percebem práticas socioespaciais de diversos atores, tais como comerciantes, consumidores, promotores imobiliários e produtores/fabricantes. As mudanças no comércio possuem relação com o espaço urbano, bem como com a cultura e os valores das sociedades (SALGUEIRO, 2001; ORTIGOZA, 2008; PINTAUDI, 2004).

As sociedades urbanizadas passam por um processo profundo de inovações dos fenômenos espaciais, nesse contexto a economia urbano-metropolitana tem um direcionamento às atividades terciárias, ou seja, há uma situação de terciarização das economias, com base na tecnologia da informação e do conhecimento técnico-científico. Como bem é salientado por Salgueiro e Cachinho (2002), o tempo contemporâneo é a época do terciário, pois se assiste a uma enorme multiplicação e progressiva diferenciação de atividades que adquire uma maior complexidade.

Face ao enorme desenvolvimento das atividades terciárias e o seu crescente papel nas economias desenvolvidas e em via de desenvolvimento, identifica-se que as grandes metrópoles têm como marcas, dentre outras: o aumento do comércio proveniente da busca das pessoas pelas mercadorias (cultura do consumo), a procura incessante de informações e serviços. Neste caminho, os pesquisadores, Rolnik e Frúgoli Junior (2001), apontam que a metrópole do terciário avançado é formada por sua vez por torres dos centros empresariais e edifícios de escritórios mesclados a shopping centers, hotéis, centros de convenção e salas de espetáculo - constituiria a imagem mais visível e evidente de uma nova ordem urbanística. As transformações do território urbano-metropolitano, dentre outras atividades, são motivadas pelo terciário avançado que se tornam importantes para refletir sobre o direcionamento do processo de urbanização dispersa. 


\section{DINÂMICAS METROPOLITANAS RECENTES A PARTIR DOS SHOPPING CENTERS NA METRÓPOLE FORTALEZENSE}

Diante das dinâmicas recentes metropolicêntricas, a metrópole contemporânea fortalezense passa a ser caracterizada por uma nova organização espacial, onde se assiste, ao mesmo tempo, à fragmentação do espaço metropolitano e à multiplicação das novas expressões de centralidade tendo participação de destaque, os shopping centers. Essas formas têm movimento próprio, delas mesmas, que as articula com outras formas, as próximas e as distantes, também iguais a ela ou diferentes dela. Dessa maneira, os shopping centers, voltados à distribuição de bens de consumo corrente, permitem tanto a reprodução do capital comercial como também a reprodução do capital do setor imobiliário e financeiro.

Parte-se da compreensão sobre a aceleração contemporânea, aliada aos interesses do capitalismo internacionalizado, tendo fortes repercussões nas relações sociais desenvolvidas nas cidades e entre as cidades, principalmente, naquelas que se transformaram em metrópoles mundiais ou nacionais, nas quais são atingidas de diferentes maneiras pela internacionalização do capital. Diante disso, questiona-se a respeito do que seria a estrutura da cidade reconhecida como moderna, o que seria a teoria urbana contemporânea e o que há de vir com a metropolização.

Vargas (2001) relata o papel das atividades terciárias nas cidades, destacando o surgimento dos shopping centers como um novo formato comercial. Essa nova forma de atividade comercial/econômica está intrinsecamente relacionada com as transformações urbanas, ao promover uma reorganização espacial das cidades brasileiras bem como de grandes centros metropolitanos. Nesta perspectiva, Pintaudi $(1992,2004)$ afirma que os shopping centers são os lugares que melhor traduzem o desabrochar das novas centralidades nas metrópoles brasileiras. Desde o seu aparecimento, os shoppings tiveram uma relação com as centralidades em formação e/ou foram elementos dinamizadores de novas centralidades.

Neste contexto, os shopping centers são empreendimentos de quase 50 anos no Brasil, o primeiro empreendimento data de 1966, o shopping Iguatemi, localizado na Avenida Faria Lima, bairro de Pinheiros, na cidade de São Paulo. Nas décadas de 1960 e 1970 ocorreu um crescimento pequeno no número desses equipamentos, a principal cidade de instalação foi São 
Paulo com um total de quatro shoppings, e tendo mais cinco distribuídos em: Brasília (1971), Londrina (1973), Fortaleza (1974), Salvador (1975) e Belo Horizonte (1979).

Os primeiros shopping centers no Brasil tiveram como localização prioritária as áreas com altas taxas de urbanização e alto poder aquisitivo. As regiões urbanas: Sudeste sob a liderança de São Paulo; no Nordeste, o primeiro shopping localizado em Fortaleza e posteriormente em Salvador; no Centro-Oeste, ocorreu em Brasília; no Sul um caso atípico, o primeiro shopping se localizou no interior do Paraná, em Londrina.

Em termos de evolução espacial dos shoppings na Região Metropolitana de Fortaleza, o surgimento se deu na metrópole fortalezense, o primeiro shopping inaugurado foi em 1974, o Center Um; no ano de 1982, foi introduzido o Iguatemi. As décadas de 1970 e 1980 são consideradas como período de gênese desses empreendimentos na capital cearense

$\mathrm{Na}$ década dos anos 1990, observou-se uma expansão e consolidação destes equipamentos, este período caracterizou-se pelo planejamento do mix (variedade de lojas e serviços) de modo que congregasse lazer e consumo, outra caraterística diz respeito à preferência da localização dos shoppings em áreas de classe média alta e média, a destacar: Shopping Avenida implantado em 1994, Shopping Aldeota instalado em 1998 (ambos no bairro da Aldeota) e do Shopping Benfica, em 1999, no bairro Benfica. Neste período tem como exceção o North Shopping, implantado em 1991, no bairro Presidente Kennedy, predominantemente de classe média baixa.

Na década dos anos 2000, as novas dinâmicas são notórias no contexto metropolitano, com a inauguração do North Shopping Maracanaú no ano de 2002, primeiro equipamento instalado na Região Metropolitana de Fortaleza, no município de Maracanaú, demonstrando sinais de extravasar dos novos hábitos de consumo e lazer para além dos limites territoriais da metrópole, dando deste modo, uma conotação cada vez mais de incorporação de características metropolitanas para a RMF. No que tange aos demais empreendimentos, observa-se a preferência pelo bairro da Aldeota com a chegada do Del Paseo implantando, no ano 2000 e pela região denominada Água Fria (expansão da classe média e classe média alta) com a chegada do Via Sul, no ano 2008 (Figura 02).

Destaca-se, que até a metade desta década dos anos 2010 presencia-se na RMF praticamente o dobro do número de shoppings ao se comparar com os anos 1974 até o final 
dos anos 2000. Fortaleza, de acordo com a Associação Brasileira de Shopping Centers ABRASCE (2014), desponta no cenário nacional com um dos maiores acréscimos de Área Bruta Locável - ABL de shopping centers do Nordeste brasileiro e do país, nesta primeira metade da década de 2010. A capital cearense é também considerada a sétima cidade no ranking em potencial de consumo no país e a segunda no Nordeste.

Figura 02: Mapa dos fluxos de localização na Região Metropolitana de Fortaleza

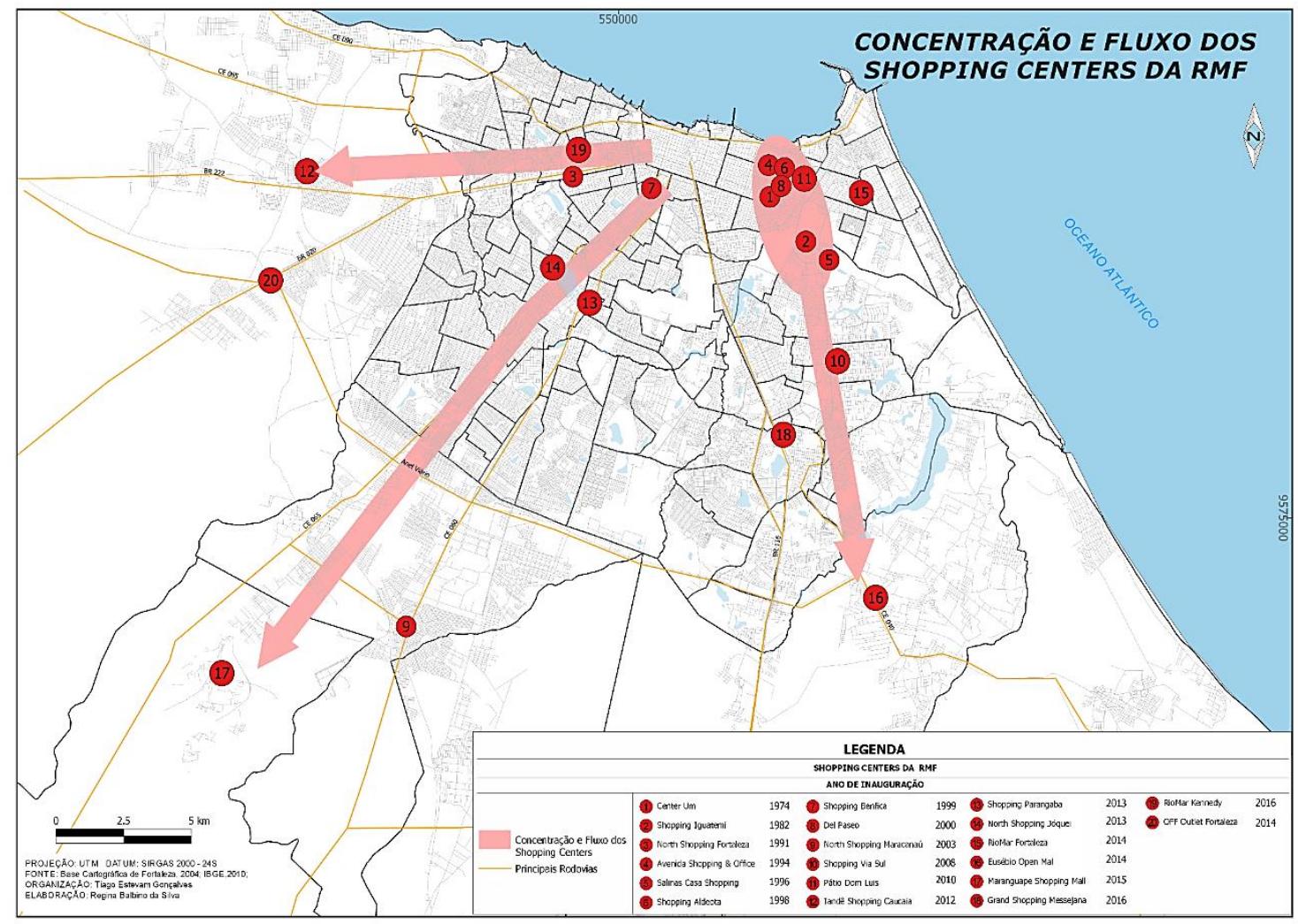

Fonte: Autor, 2015.

Silva (2005, p. 108-109) afirma que “[...] a dinâmica recente dos espaços urbanos e metropolitanos no Brasil dá sinais de mudança em seu interior, indicando feições territoriais ligadas ao processo de reestruturação produtiva dominante no país". Inseridos em tal dinâmica, os shopping centers ocupam parcelas significativas do tecido urbano e metropolitano fortalezense, provocando rápidas alterações estruturais do uso como resultado 
da especulação e da obsolescência, sendo assim sinais mais reconhecíveis da dinâmica urbana (HARVEY, 2005).

Neste contexto, a RMF vem recebendo, com maior ou menor peso, as influências da presença de novos agentes econômicos, na maior parte dos casos, empresas de grande porte econômico articuladas aos interesses de inovação comercial-imobiliária. São, sobretudo, agentes que trazem consigo novas práticas e formas de atuação e expressam, por meio da produção de formas comerciais e imobiliárias, estratégias de desenvolvimento do capitalismo contemporâneo. Percebeu-se nesta década uma expansão no número de shoppings inaugurados em bairros de Fortaleza até então pouco explorados, como Parangaba, Jóquei Clube e Papicu, bem como na RMF, nos municípios de Caucaia e Eusébio. Confirmando a tendência de expansão, foi inaugurado em 2012, o Iandê Shopping, em Caucaia; no ano de 2013, o Shopping Parangaba, no bairro Parangaba; o North Shopping Jóquei, em 2013, no Jóquei Clube; o Shopping RioMar, em 2014, no bairro Papicu, todos na capital, Fortaleza; ainda em 2014, foi implantado no município de Eusébio, o Open Mall. Para o ano de 2015, há previsão de inauguração do Gran Shopping Messejana, também em Fortaleza e o Maranguape Shopping Mall, em Maranguape.

No processo de transformação do espaço urbano de Fortaleza pelos shoppings centers é imprescindível também observar a ação do Estado que entra em cena como um grande articulador. A atuação do Estado é complexa e variável, uma vez que tenta atender aos interesses dos demais agentes urbanos. Neste sentido há uma relação das politicas públicas urbanas em Fortaleza e as Operações Urbanas Consorciadas nas áreas de instalação dos shoppings: RioMar e North Shopping Jóquei.

Desta maneira, a Operação Urbana consorciada Lagoa do Papicu foi estabelecida pela lei no 9857, de 22 de dezembro de 2011 e está relacionada à instalação do Shopping Rio Mar, nesta área estava localizada a antiga fábrica da Brahma, além do shopping do grupo pernambucano João Carlos Pães de Mendonça esta área terá um grande empreendimento imobiliário, contando com uma área total aproximada de $90.000 \mathrm{~m}^{2}$ - Evolution Central Park com torres residenciais, comerciais e hotel através da parceira do grupo Otoch Empreendimentos e a incorporadora Moura Dubeux. 
Com relação à Operação Urbana Consorciada Jockey Clube foi estabelecida pela lei $\mathrm{n}^{\circ}$ 9333, de 28 de dezembro de 2007, realizada na área do antigo Jockey Clube Cearense, nesta área ocorreu a construção do Hospital da Mulher pela Prefeitura Municipal de Fortaleza, também, foi instalado o North Shopping Jóquei Clube, em 2013, através de parceria dos grupos Ancar Ivanhoe Shopping Centers e SG Participações e apresentam-se com intensidade de fluxos de empreendimentos imobiliários da Diagonal Engenharia com torres de apartamentos.

Nesta atual fase, os shoppings apresentam com novos agentes envolvidos, com novos processos muitas vezes associados à produção de condomínios e a torres comerciais na área de entorno, evidenciando assim novas paisagens urbanas de rupturas da continuidade do território urbano, também no bojo da questão, os shoppings tendem a apresentar novas lógicas de localização, mostrando uma relação direta com a intensificação da produção imobiliária em novas áreas da RMF.

A diversidade de iniciativas de produção de shopping centers estabelece novas relações entre centro e periferia, as quais têm aberto uma lacuna que apresenta mais interrogações que respostas. Diante desses processos de redefinição de centralidades e produção metropolitana, observa-se a complexa atuação das inovações espaciais do setor terciário - os shopping centers - na nova realidade socioespacial que ganham novos conteúdos sociais, econômicos invadindo paulatinamente a capital cearense e seu espaço metropolitano (DANTAS, 2009; RUFINO, 2012).

A redefinição de centralidade no território metropolitano, portanto tem obtido novas dimensões decorrentes das mudanças em curso nas cidades nos últimos tempos, tornando-se objeto de estudos específicos, sobretudo desde a última década do século XX tem os grandes equipamentos como os shoppings, um dos elementos mais importantes para essa tendência na metrópole de Fortaleza (DIOGENES, 2012). Assim, de acordo com as novas dinâmicas econômicas e transformações do território metropolitano de Fortaleza, observa-se no atual modelo uma diversidade de centralidade, descontinuidade de fluxos, novas articulações de centros e periferias, construindo novas morfologias.

Os shopping centers, com sua natureza agregadora de atividades, aglutinando diversos ramos do comércio, serviços e lazer, aliada ao seu porte e à sua escala, passaram a ocupar 
parcelas significativas do espaço, como exemplos de grandes áreas de consumo, fazem parte da dinâmica da metrópole contemporânea fortalezense. Nesta última década, ocorreu um verdadeiro boom desse tipo de produção imobiliária-comercial em diversas áreas da cidade e de seu espaço metropolitano atrelado às novas dinâmicas de internacionalização da economia mundial, sendo diretamente afetada pelo processo de flexibilização da economia contemporânea.

Deste modo, entende-se que as relações entre metrópole, shopping center e consumo são bastante estreitas, estando atreladas às novas dinâmicas de internacionalização da economia mundial, sendo diretamente afetada pelo processo de flexibilização da economia contemporânea. Esta relação não se dá apenas em nível econômico, mas tem se expressado notoriamente através de novas linguagens de dinâmica territorial.

Assim, a estrutura do comércio, com a inserção das grandes superfícies comerciais, tem acompanhando ou antecipado, configurações espaciais e sociais das cidades, por exemplo: a mudança nas perifeiras urbanas incentivada pelo comércio é um movimento que não pode ser separado da população e do surgimento de novos dispositivos de polaridades econômicas e culturais. Este movimento espacial não pode ser considerado em si, mas é também um aspecto de transformações das grandes empresas mundiais que moveram a formação da sociedade de consumo. É importante salientar que além de sua função comercial singular os shopping centers em Fortaleza tornam-se peças fundamentais na revitalização e valorização de determinados espaços, na alteração de áreas comerciais tradicionais e da dinâmica de bairros meramente residenciais, na mudança do fluxo de trânsito, na captação de investimentos estatais para infraestrutura urbana. A localização, a estrutura e o funcionamento desses estabelecimentos interferem no processo de reprodução do espaço urbano e metropolitano, já que o comércio contém e produz centralidade.

\section{CONSIDERAÇÕES FINAIS}

Os shopping centers foram impulsionados de acordo com as transformações vivenciadas pela dinâmica capitalista no fím do século XIX e início do século XX. A formação e principalmente a difusão dos shoppings centers nos Estados Unidos possui os seguintes 
fatores preponderantes: expansão automobilística norte-americana que provocou a necessidade dos centros comerciais de se adequarem a essa expansão, disponibilizando espaços de estacionamento; o aumento do poder de compra da população; processo de descentralização das residências para zonas periféricas, ou seja, os shoppings estão relacionados ao fenômeno de surgimento e expansão dos subúrbios, do advento do automóvel e das alterações nas áreas metropolitanas das cidades norte-americanas.

No contexto brasileiro, com o processo de urbanização e metropolização, dado pelo crescimento das cidades, transformações urbanas e problemas urbanos, pobreza, trânsito e violência, tornaram-se os elementos que possibilitaram o surgimento dos shoppings nos anos 1960. Esses empreendimentos com o intuito de criar uma cidade ideal, em que não se apresenta as diversas intempéries tiveram, principalmente, nas últimas décadas uma expansão vertiginosa em diversos contextos metropolitanos do Brasil, a destacar a Região Metropolitana de Fortaleza.

Os shoppings centers têm se instalado em novos municípios da região metropolitana de Fortaleza, então, sendo um elemento material e simbólico do processo de metropolização contemporânea, assim, evidencia-se a introdução de um processo de modernização do mercado imobiliário, com investimento em grandes empreendimentos de caráter imobiliáriocomercial como - os shoppings- que repercutem na abertura da fronteira da expansão do capital, que ao buscar novas parcelas do território urbano-metropolitano fortalezense, tendem a resultar na valorização e enobrecimento de determinadas áreas metropolitanas.

Estes empreendimentos apresentam diversas atividades simultâneas que vão além da simples compra e venda de produtos a apresentações culturais que vem a repercutir em processos sociais. Mostram-se, então, como uma forma espacial de forte atuação no território metropolitano fortalezense. Ao considerar o shopping center como investimento comercialimobiliário estão intimamente ligando-o ao setor da indústria imobiliária sob a ação de diversos agentes: empresas de incorporação, imobiliárias, grupos de industriais, financeiros, fundos de pensão, empresas de administração e marketing; investidores institucionais. Esses agentes participam de diferentes momentos como: o planejamento, o desenvolvimento, a comercialização e a administração. 
Assim, a economia metropolitana fortalezense está cada vez mais se apoiando na expansão do setor terciário avançado que congrega serviços, comércio e finanças. $\mathrm{O}$ atual investimento vultoso no setor de shoppings faz com que esses equipamentos se revelem a partir de diversas facetas como: produto imobiliário e de consumo, no estabelecimento de novas relações do modo de vida metropolitano através dos padrões de consumo e lazer e dentre outras pela difusão territorial em novas áreas para a realização do capital.

Neste contexto, é imprescindível compreender a metropolização contemporânea fortalezense e seus desdobramentos diante do quadro atual da dinâmica imobiliária-comercial desencadeada por esses empreendimentos - os shopping centers - que representam formas e conteúdos da sociedade pós-moderna, em que é de modo dialético produto e produtor socioespacial, no qual é evidenciado a partir de padrões arquitetônicos, socioeconômicos, espaciais e simbólicos. Ao considerar que o espaço urbano-metropolitano é revelador de um tempo que se materializa, pode-se afirmar, então, que neste contexto os shoppings são palco de consumo e talvez uma das melhores ilustrações da relação tempo/espaço na metrópole contemporânea.

\section{REFERÊNCIAS BIBLIOGRÁFICAS}

ABRASCE, ASSOCIAÇÃO BRASILEIRA DE SHOPPING CENTERS. Disponível em <http://www.portaldoshopping.com.br/>. Acesso em: 30 nov. 2014.

ASCHER, F. Metápolis: Acerca do futuro da cidade. Tradução: Álvares Domingues. Oeiras, Portugal: Celta editora, 1998.

CACHINHO, H. O comércio retalhista português: pós-modernidade, consumidores e espaço. Lisboa: Gabinete de Estudos e Prospectiva Econômica do Ministério da Economia, 2002.

COSTA, M. C. L. Fortaleza: expansão urbana e organização do espaço. In: SILVA, J. B. da; CAVAlCANTE, T. C.; DANTAS, E. W. C. Ceará: um novo olhar geográfico. Fortaleza: Edições Demócrito Rocha, 2005.

COSTA, M. C. L.; AMORA, Z. B. Fortaleza na rede urbana brasileira: de cidade à metrópole. In: COSTA, M. C. L.; PEQUENO, R. (editores). Fortaleza: transformações na ordem urbana. Rio de Janeiro: Letra Capital, Observatório das Metrópoles, 2015.

DANTAS, E. W. C.; SILVA, J. B. da. A formação histórica da metrópole e principais tendências de desenvolvimento. In: PEQUENO, L. R. B. (Org.). Como anda Fortaleza. Rio de Janeiro: Letra Capital/Observatório das Metrópoles, 2009. 
DIÓGENES, B. H. N. Dinâmicas urbanas recentes da área metropolitana de Fortaleza. 2012. (Tese de Doutorado), FAU-USP, São Paulo, 2012.

GONÇALVES, T. E.; COSTA, M. C. L. O papel do North shopping no processo integração metropolitana de Fortaleza e Caucaia. Geografia Ensino \& Pesquisa (UFSM), v. 16, n.1, p. 55-70, jan./jun, 2012.

HARVEY, D. A produção capitalista do espaço. São Paulo: Annablume, 2005.

LEFEBVRE, H. A Revolução Urbana. Belo Horizonte: EDUFMG, 2004.

LENCIONI, S. Uma nova determinação do urbano: o desenvolvimento do processo de metropolização do espaço. In: CARLOS, A. F. A.(org.). LEMOS, A. I. G. (org.). Dilemas Urbanos - Novas Abordagens sobre a cidade. São Paulo: Contexto, 2005.

ORTIGOZA, S. A. G. A metrópole pós-moderna como centro do consumo: notas sobre São Paulo (Brasil) e Lisboa (Portugal). Revista Estudos Geográficos. Rio Claro, v. 6, n. 1, 2008. PEREIRA JÚNIOR, E. Região, Cidade e Metrópole no contexto do novo processo de industrialização do Ceará. In: XIII Simpósio Nacional de Geografia Urbana. Anais... Rio de Janeiro, 2013.

PINTAUDI, S. M.; FRÚGOLI JÚNIOR, H. (Orgs). Shopping Centers: Espaço, Cultura e Modernidade nas cidades brasileiras. São Paulo: Editora Estadual Paulista, 1992.

PINTAUDI, S. M. Para uma leitura das formas de comércio varejista na cidade. Revista Cidades. Presidente Prudente: Grupo de Estudos Urbanos, v. 7, n. 11, 2004.

ROLNIK, R.; FRÚGOLI JÚNIOR, H. Reestruturação urbana da metrópole paulistana: a Zona Leste como território de rupturas e permanências. Cadernos Metrópoles, nº, p.43-66, $2^{\circ}$ semestre, 2001.

RUFINO, M. B. C. Incorporação da Metrópole: Centralização do capital no imobiliário e na nova produção do espaço em Fortaleza. Tese de Doutorado - FAUSP. São Paulo, 2012.

SAlguEIRO, T. B. Lisboa, Periferia e Centralidades. Celta: Oeiras, Portugal, 2001.

SALGUEIRO, T. P.; CACHINHO, H. Comércio, Consumo e (re) produção do espaço urbano. Apontamentos de Geografia. Série Investigação, $n^{\circ}$. 14. Centro de Estudos Geográficos, Lisboa, 2002.

SEABRA, O. Da Cidade à metrópole. Revista Geografares, n.9, p.40-79, Jul/Dez, 2011.

SILVA, J. B. da. A região metropolitana de Fortaleza. In: SILVA, J. B. da; CAVALCANTE, T. C.; DANTAS, E. W. C. (Org.). Ceará: um novo olhar geográfico. Fortaleza: Edições Demócrito Rocha, 2005.

SILVA, J. B. da. Quando os incomodados não se retiram: uma análise dos movimentos sociais em Fortaleza. Fortaleza: Multigraf, 1992.

SOUZA, M. S. O crescimento das cidades no Ceará e sua evolução. In SILVA, J. B. da. (org.). $4^{\circ}$ Simpósio Nacional de Geografia Urbana. Anais... Fortaleza, 1995.

SOUZA, M. S. Análise da Estrutura Urbana. In: SILVA, J. B. COSTA, M. C. L. da; DANTAS, E. W. C. (org.) De cidade à metrópole: (Trans) formações urbanas em Fortaleza. Fortaleza: Edições UFC, 2009.

VARGAS, H. C. Espaço terciário: o lugar, a arquitetura e a imagem do comércio. São Paulo: SENAC, 2001. 
Recebido em novembro 2015. Aceito em agosto de 2017. 